\title{
Repeated Dermal Paraphenylenediamine Exposure Induces Systemic Biochemical and Histological Changes in Adult male Albino Rats
}

\section{Hend ElHelaly ${ }^{1}$ and Safaa M. Shaker ${ }^{2}$}

\author{
${ }^{1}$ Department of Forensic Medicine and Clinical Toxicology \\ ${ }^{2}$ Department of Histology \\ Faculty of Medicine, Ain-Shams University, Cairo, Egypt.
}

\begin{abstract}
Paraphenylenediamine (PPD) is a synthetic compound that is widely used as a hair dye. This study investigated biochemical and histological effects after repeated PPD dermal application. 30 adult male albino rats $(200 \pm 20 \mathrm{gms})$ were classified into two groups; group I, (control group) included negative and positive control subgroups, each consisted of 10 rats and group II (tested group). Tested group was subjected to repeated topical PPD application in a dose of $10 \mathrm{mg} / \mathrm{kg}$ for 90 days. All groups were investigated for these laboratory biochemical parameters: Serum creatine phosphokinase CPK-MB, aspartate (AST) and alanine transferases (ALT), serum creatinine (S. Creat.), blood urea nitrogen (BUN) as well as serum potassium. All the mentioned parameters showed significant increase when compared to control group. ECG was done and revealed significant decrease of pulse rate and significant prolongation of PR, QRS and QT intervals in tested group. In-addition, to biochemical and ECG investigations; histological examination was done for; cardiac, hepatic, renal and testicular tissues. Cardiac, hepatic, renal, and testicular tissues of tested group showed evident changes. These changes were more obvious in Cardiac, renal, and testicular tissues when compared to control.
\end{abstract}

\section{Introduction}

$\mathrm{P}$ araphenylenediamine (PPD/1,4diaminobenzene), a monocyclic aryl amine, is widely used in almost all hair dye formulations. It is also used as photographic developing agent, an intermediate in the manufacture of azo dyes, antioxidant, and accelerator for rubber vulcanization. PPD is added to henna to accelerate the dyeing and drying process to strengthen and darken the color, to enhance the design pattern of the tattoo, and to make the tattoo lasts longer (Rauscher et al., 2004). PPD and its metabolites might be allergenic, mutagenic and toxic. Clinical presentation of acute PPD intoxication is usually dominated by paresis, cola-colored urine, angioedema and asphyxia (Kallei et. al., (2005).

PPD intoxication following oral ingestion could be an important cause of acute renal failure in Sudan, Morocco and the Indian Subcontinent. Repeated and prolonged exposure to PPD may also be associated with Chronic Kidney Disease (Hamdouk et. al., 2011).

\begin{abstract}
Aim of the work
This study aimed to investigate systemic toxicities of PPD especially after repeated dermal exposure.

\section{Materials and methods}

\section{Material}

The tested chemical paraphenylenediamine (PPD), CAS No (106-50-3) was purchased from Sigma Chemical Company in the form of white powder then dissolved in distilled water.
\end{abstract}

\section{Animals}

Thirty adult male albino rats were conducting in this study and classified into two groups:

\section{I- Control group (group I)}

This group was sub-classified into two subgroups each consisted of 10 rats, as follows: 
- Negative control subgroup Ia: Ten adult male albino rats were only housed and kept in the same environment without handling to demonstrate the normal basic parameters.

- Positive control subgroup Ib: Ten adult male albino rats which had distilled water application over a bared skin area of $4 \mathrm{~cm}$ diameter for 90 days were used to show the effect of stress of handling, administration and vehicle loading.

\section{II- Tested group (group II)}

This group consisted of 10 adult male albino rats exposed to $10 \mathrm{mg} / \mathrm{kg} /$ day of PPD for 90 days.

\section{Technique of administrations}

One gram of PPD was dissolved in $100 \mathrm{ml}$ warm distilled water with shaking. It was applied with a plastic syringe and then spread easily with a spatula over the shaved dorsal skin area of $4 \mathrm{~cm}$ diameter (Gouma et. al., 2011). It was applied for 90 days according to SCCP, (2006) who stated that no adverse effects were detected (NOAEL) at dose less than $5 \mathrm{mg} / \mathrm{kg}$ PPD administration.

This work represents a study investigating systemic effects of dermal application using a dose; double the NOAEL and that is equal to $5.8 \%$ of LD50. Besides, the dose and timing of mimic PPD dermal exposure for workers as hair dresser and textile manufacturing. All rats were housed in proper ventilated, humidity-controlled cages. Rats had free access to water and food during the experimental period.

\section{Parameters}

After 90 days of continuous exposure, electrocardiograph (ECG) was done then rats were sacrificed under $\mathrm{Na}$ thiopental anesthesia, and subjected to following parameters:

\section{Biochemical parameters}

Blood samples were collected from jugular veins in non EDTA tube for laboratory parameters which included cardiac biomarker in the form of serum creatine phosphokinase (CPK-MB), renal function tests (serum creatinine (S. creat) and blood urea nitrogen (BUN), serum potassium $\left(\mathrm{K}^{+}\right)$, and hepatic alanine transferase (ALT) and aspartate transferase (AST).

Measurements of CPK-MB mass were done using CPK-MB STAT methods (Roche Diagnostics, Tutzing, Germany). Other biochemical parameters were recorded using spectrophotometer (Spekol 11 UV visible spectrophotometer ACHTUNG, Vor offnen, Netzstecher Ziehen). All parameters were done at Medical Research Center, Ain Shams University Hospitals.

\section{Histological parameters}

The exposed area of skin, heart, liver, kidneys and testes of each animal of both groups (group I and group II) were removed and processed to prepare paraffin blocks. Paraffin blocks were cut to obtain sections of $5 \mu \mathrm{m}$ thickness for $\mathrm{H} \& \mathrm{E}$ staining. PAS staining was used to stain some sections of the testes (Bancroft and Gamble, 2007).
Some kidney specimens were fixed in formol glutaraldehyde and processed for electron microscopic examination (Bancroft and Cook, 1994) using TEM1010- EXII (Joel, Tokyo, Japan) at the Regional Mycology and Biotechnology Unit, AL Azhar University, Cairo, Egypt.

\section{Ethical considerations}

Well ethical approved conditions for animal housing and handling were considered. In-addition, the experimental protocol followed the regulations for administration and painless scarification approved by Ethical Committee for Scientific Research, Faculty of Medicine Ain Shams University.

\section{Statistical analysis}

The obtained data were expressed as numbers, percent, mean and standard deviation using student t-test by SPSS V17.

\section{Results}

Table 1 showed that there was non-significant difference between both negative and positive control subgroups regarding all the tested parameters.

Based on the data analysis of table (1) where there was a non-significant difference as regards all biochemical parameters as well as the ECG parameters between both control subgroups. So, all the following tables showed the comparison between single one control group I and a tested group II.

In-addition, histological examination of exposed skin, heart, liver, kidney ant testes tissues also showed no differences during examination between both control subgroups.

Tables 2 and 3 showed that there was significant difference between tested group and control group as regards cardiac biochemical marker CPK-MB. There was significant increase of CPK-MB in tested group (group II) in comparison to control group (group I). Moreover, there were significant difference regarding ECG changes in tested group when compared to control group. There was significant decrease of heart rate as well as significant prolongation of PR, QT and QRS widening in group II when compared to group I.

\section{Histological result of the heart}

$\mathrm{H} \& \mathrm{E}$ stained sections of left ventricle of the heart of control group showed regularly arranged cardiac muscle fibers (figure 4). They appeared branching, anastomosing and running in different directions. They had acidophilic sarcoplasm and central oval vesicular nuclei (figure 5). $\mathrm{H}$ $\&$ E stained sections of left ventricle of the heart of group II showed focal areas where cardiac muscle fibers lost their continuity and had pale sarcoplasm. At these area mononuclear cellular infiltration was observed (figures 6 and 7) in some sections.

Table 4 showed the incidence of cardiac histological changes among control and tested groups as regards; myocardial degeneration, inter-myocardial 
congestion and cellular infiltration. The table showed that, myocardial degeneration in all tested animals $(100 \%)$, myocardial congestion and cellular infiltration was evident in $(50 \%)$ of tested group.

Table 5 showed that there was significant difference between tested group and control group regarding liver enzymes. It showed also there was significant rise of hepatic enzymes ALT and AST in tested group when compared to control group.

\section{Histological result of the liver}

Histological examination of $\mathrm{H} \& \mathrm{E}$ stained sections of rat liver of group I showed branching and anastomosing cords of hepatocytes around central veins. The cords were separated by blood sinusoids that lined by flat endothelial cells. Hepatocytes were polygonal had acidophilic granular cytoplasm and central rounded vesicular nuclei. Branches of hepatic artery, bile duct (figure 8 ) and portal vein could be seen at the portal tracts.

On histological examination of $\mathrm{H} \& \mathrm{E}$ stained sections of rat liver of group II, mononuclear cellular infiltration could be detected in some portal tracts (figure 9). In addition, this cellular infiltration was evident in Eighty percent $(80 \%)$ of rats of group II.

\section{Histological results of the kidney}

Table 6 showed that there was significant difference between tested group and control group as regards S. creat, BUN and $\mathrm{K}^{+}$levels. Moreover, there was significant increase of S. creat, $\mathrm{BUN}$ and $\mathrm{K}^{+}$levels in tested group (group II) when compared to control group (group I).

On examination of $\mathrm{H} \& \mathrm{E}$ stained sections of the kidney of the control rat, its parenchyma was divided into cortex and medulla. The cortex comprised renal corpuscles, proximal and distal convoluted tubules. The renal corpuscle was formed of a glomerulus and Bowman's capsule. The glomerulus appeared lobulated with evident glomerular capillaries. The Bowman's capsule was formed of a parietal layer which was lined with flat squamous cells resting on a thin basement membrane (figure 10) and a visceral layer; the glomerular epithelium; that covers each glomerular capillary. The proximal convoluted tubules (P.C.Ts) had narrow lumens and were lined with a single layer of pyramidal cells having indistinct boundaries. The cells showed acidophilic granular cytoplasm, rounded basal nuclei and apical brush border (figure10). The distal convoluted tubules (D.C.Ts) were characterized by their slightly wider lumen. The lining cells were cubical with acidophilic cytoplasm and rounded central nuclei (figure 10). The renal medulla showed many cut sections of loops of Henle, collecting tubules and blood capillaries. The lining cells of the collecting tubules appeared cubical with pale clear cytoplasm and rounded central nuclei (figure 11).

On electron microscopic examination of the kidney cortex we focused on the proximal convoluted tubules. The epithelial cells of PCT lied on a basement membrane. They were characterized by presence of apical microvilli, vacuoles, euchromatic nucleui. Mitochodria were concentrated at the basal part of PCTs and had certain pattern. They appeared elongated lodged in compartment made by the basal infoldings of cell membrane of PCTs (figures 12, 13 and 14).

Histological examination of $\mathrm{H} \& \mathrm{E}$ stained sections group II, showed that the lesion was focal and mainly tubular. Tubular changes mainly involved the P.C.Ts to much more extent than the D.C.Ts. In some sections the P.C.Ts and the D.C.Ts showed vacuolation of their lining cells. The cells of some tubules had pyknotic nuclei. Minimal cellular infiltration could be detected (figure 15) in the interstitium. In other sections, there was_marked vacuolation and degeneration of the PCTs and DCTs where desquamation of the tubular epithelial lining was seen inside the lumen of many tubules. RBCs were evident in the peritubular capillaries (figure 16). Examination of the medulla showed the presence of casts in the lumina of the collecting tubules and slight vacuolation of their lining (figure 17).

On electron microscopic examination of the kidney cortex of group II, the main damage affected the epithelial lining of PCT. It showed irregular nuclei and electron lucent areas of cytoplasm. Microvilli were apparent at certain sites and absent at others. Mitochondria lost their normal arrangement at basal part of PCTs and had abnormal shapes (figures 18 and 19).

Table 7 showed the incidence of kidney histological changes among control and tested groups as regards; vacuolated cytoplasm of tubular epithelial lining, pyknotic nuclei of tubular epithelium lining, desquamated epithelium of tubular lumen and cellular infiltration. The table showed that, there was cytoplasmic vaculation of renal tubular epithelial lining in all tested animals $(100 \%)$ and nuclear pyknosis was evident in $(90 \%)$ of tested group (group II). In-addition, desquamated renal tubular epithelium was evident in $(80 \%)$ of group II. However, cellular infiltration was observed only in (40\%) of tested animals (group II).

\section{Histological results of the testes}

Examination of H \& E sections of group I revealed that the testis was formed of rounded or oval seminiferous tubules (Sts) separated by interstitial tissue (figure 20). Each seminiferous tubule (St) was surrounded by myoid cells and lined by2 types of cells; spermatogenic cells and Sertoli cells. The spermatogenic cells included spermatogonia, primary and secondary spermatocytes, and early and late spermatids. Spermatogonia were basally situated adjacent to the basement membrane. They appeared rounded with rounded nuclei. Primary spermatocytes were the largest cells and showed various stages of chromatin coiling. Secondary spermatocytes were small and hardly seen. Early spermatid was very small rounded cell located in the adlumenal compartment. 
Late spermatids were attached to the apices of Sertoli cells and had deeply stained nucleui (figure 21) and exhibited PAS positive reaction (figure 22). Sertoli cells were resting on the basement membrane with irregular indistinct outlines. They had ovoid vesicular nuclei (figure 21). In between the tubules, the interstitial cells of Leydig could be seen close to blood vessels. They had rounded vesicular nuclei and vacuolated cytoplasm (figure 21). In PAS stained sections, intense P.A.S positive reaction was detected in the basement membrane of Sts and also PAS reaction could be detected in the interstitial tissue (figure 22).

Examination of $\mathrm{H} \& \mathrm{E}$ sections of group II revealed affection of the structure of the testes. Some STs were irregular with disorganization of the lining epithelium (figure 23). Some tubules showed apparent reduction of epithelial lining and spermatogenic cells had pyknotic nuclei so that the different types of spermatogenic cells couldn't be identified (figures 23, 24, and 25). Exudate (figures23 and 24) and congestion of blood vessels (figure 25) could be seen in the interstitial tissue.

PAS stained sections of this group showed apparent decrease of the PAS positive reaction in the basement membrane (figure 26 ).The basement membrane appeared separated in some tubules (figures 24 and 26).

Table (8) showed that there was evident testicular histological changes among animals in tested group (group II). Spermatogenic cells with pyknotic nuclei were observed in $80 \%$ of animals. However, interstitial congestion and exudate were recorded only in $50 \%$ of animals.

Table 1: Student t-test of serum biochemical parameters; Serum Creatinine phosphokinase (CPK-MB), Serum Creatinine (S. creat.), Blood Urea Nitrogen (BUN) and serum potassium $\left(\mathrm{K}^{+}\right)$levels. In-addition, to hepatic enzymes Alanine Transferase (ALT) and Aspartate Transferase (AST). ECG recordings; Heart Rate (HR), PR interval (PR), (QRS) and QT interval (QT) between negative and positive control subgroups (each group consisted of 10 rats)

\begin{tabular}{|c|c|c|c|c|}
\hline Parameters Groups & $\begin{array}{l}\text { Negative Control Subgroup Ia } \\
(\text { mean } \pm \text { SD) }\end{array}$ & $\begin{array}{c}\text { Positive control Subgroup Ib } \\
(\text { mean } \pm \text { SD })\end{array}$ & $P$ value & $\mathbf{t}$ \\
\hline CPK-MB U/L & $191.04 \pm 72.722$ & $269.44 \pm 39.798$ & 0.0674 & 2.115 \\
\hline S. Creat. mg/dl & $0.3700 \pm 0.1086$ & $0.3720 \pm 0.09203$ & 0.9757 & 0.03141 \\
\hline BUN. mg/dl & $30.960 \pm 3.411$ & $29.640 \pm 3.603$ & 0.5683 & 0.5949 \\
\hline $\mathrm{K}^{+} \mathrm{meq} / \mathrm{dl}$ & $4.700 \pm 0.4690$ & $5.120 \pm 0.5263$ & 0.2195 & 1.332 \\
\hline ALT U/L & $30.960 \pm 3.411$ & $30.360 \pm 3.684$ & 0.7961 & 0.2672 \\
\hline AST U/L & $68.240 \pm 10.398$ & $68.180 \pm 7.781$ & 0.9920 & 0.01033 \\
\hline $\mathrm{HR} / \mathrm{min}$ & $367.00 \pm 4.690$ & $366.6 \pm 3.647$ & 0.8841 & 0.1505 \\
\hline PR msec. & $38.380 \pm 1.517$ & $36.600 \pm 1.817$ & 0.1311 & 1.682 \\
\hline QRS msec. & $36.360 \pm 1.573$ & $36.880 \pm 1.681$ & 0.6271 & 0.5051 \\
\hline QT msec. & $74.580 \pm 4.726$ & $74.340 \pm 3.034$ & 0.926 & 0.09556 \\
\hline
\end{tabular}

$P$ value significant when $<0.05$

Table 2: Student t-test of serum creatinine phosphokinase (CPK-MB) between group I and group II (each group consisted of 10 rats)

\begin{tabular}{|l|c|c|c|c|}
\hline Group & Group I & Group II & t-test & P value \\
\hline $\mathrm{CPK}-\mathrm{MB}$ U/L (mean $\pm \mathrm{SD})$ & $191.04 \pm 72.722$ & $631.04 \pm 318.42$ & 2.998 & 0.0103 \\
\hline
\end{tabular}

$P$ value significant when $<0.05$

Table 3: Student $t$ - test of ECG changes; Heart Rate (HR), PR interval prolongation (PR), QRS widening (QRS) and QT interval prolongation (QT)between group I and group II (each group consisted of 10 rats)

\begin{tabular}{|c|c|c|c|c|}
\hline Group Parameter & $\mathrm{HR} / \mathrm{min}$ & PR (msec.) & QRS (msec.) & QT (msec.) \\
\hline Group I & $360.50 \pm 17.852$ & $35.333 \pm 2.805$ & $35.400 \pm 1.789$ & $73.800 \pm 2.263$ \\
\hline Group II & $238.11 \pm 85.196$ & $73.000 \pm 19.774$ & $39.556 \pm 3.678$ & $115.67 \pm 10.452$ \\
\hline $\mathrm{T}$ test & 20.479 & 23.243 & 260.68 & 52.334 \\
\hline $\mathrm{p}$ value & $<0.0001$ & $<0.0001$ & $<0.0001$ & $<0.0001$ \\
\hline
\end{tabular}

$P$ value significant when $<0.05$ 
Table 4: Percentage of cardiac histological changes in group I and group II (each group consisted of 10 rats)

\begin{tabular}{|c|c|c|}
\hline Histologic change $\quad$ Group & Group I & Group II \\
\hline Myocardial degeneration (\%) & 0 & 100 \\
\hline Inter-myocardium congestion (\%) & 0 & 50 \\
\hline Cellular infiltration $(\%)$ & 0 & 50 \\
\hline
\end{tabular}

Table 5: Student t-test of serum ALT and AST levels between group I and group II (each group consisted of 10 rats)

\begin{tabular}{|l|c|c|}
\hline Group & ALT U/L (mean \pm SD) & AST U/L (mean \pm SD) \\
\hline Group I & $30.96 \pm 3.411$ & $92.17 \pm 13.45$ \\
\hline Group II & $37.56 \pm 3.051$ & $98.24 \pm 10.398$ \\
\hline $\mathrm{t}$ test & 3.806 & 3.470 \\
\hline P value & 0.0022 & 0.0041 \\
\hline
\end{tabular}

$P$ value significant when $<0.05$

Table 6: Student t-test of S.Creat., BUN and S.K ${ }^{+}$between group I and group II (each group consisted of 10 rats)

\begin{tabular}{|l|c|c|c|}
\hline Group & S. Creat. $\mathbf{~ m g} / \mathbf{d l}(\mathbf{m e a n} \pm \mathbf{S D})$ & BUN mg/dl (mean \pm SD) & K meq/l (mean \pm SD) \\
\hline Group I & $0.37 \pm 0.1086$ & $30.96 \pm 3.411$ & $4.7 \pm 0.4690$ \\
\hline Group II & $0.938 \pm 0.2497$ & $52.8 \pm 6.233$ & $21.55 \pm 8.529$ \\
\hline $\mathrm{t}$ test & 4.795 & 7.223 & 4.332 \\
\hline P value & 0.0004 & $<0.0001$ & 0.0008 \\
\hline
\end{tabular}

$P$ value significant when $<0.05$

Table 7: Percentage of kidney histological changes of group I and group II (each group consisted of 10 rats)

\begin{tabular}{|c|c|c|}
\hline Histologic change & Group I & Group II \\
\hline Vacuolated cytoplasm of epithelium lining the tubules (\%) & 0 & 100 \\
\hline Pyknotic nuclei of epithelium lining the tubules (\%) & 0 & 90 \\
\hline Desquamated epithelium in lumen of tubules (\%) & 0 & 80 \\
\hline Cellular infiltration $(\%)$ & 0 & 40 \\
\hline
\end{tabular}

Table 8: Percentage of testicular histological changes of group I and group II (each group consisted of 10 rats)

\begin{tabular}{|l|c|c|}
\hline Histologic change Group & Group I & Group II \\
\hline Spermatogenic cells with pyknotic nuclei (\%) & 0 & 80 \\
\hline Interstitial blood vessel congestion (\%) & 0 & 50 \\
\hline Interstitial exudates (\%) & 0 & 50 \\
\hline
\end{tabular}

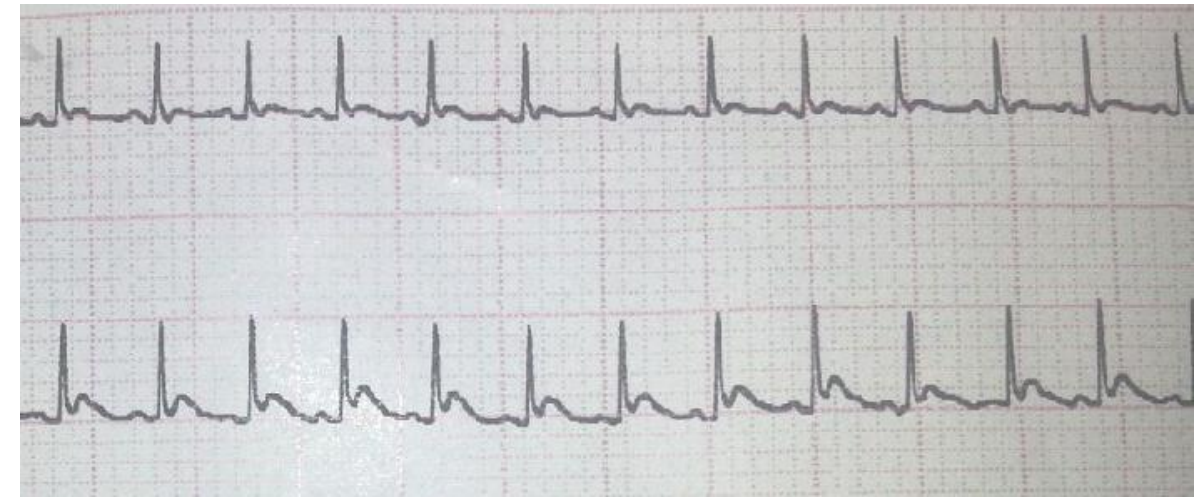

Figure (1): Regular sinus rhythm with rate 335 beat/minute in group I (control group). 


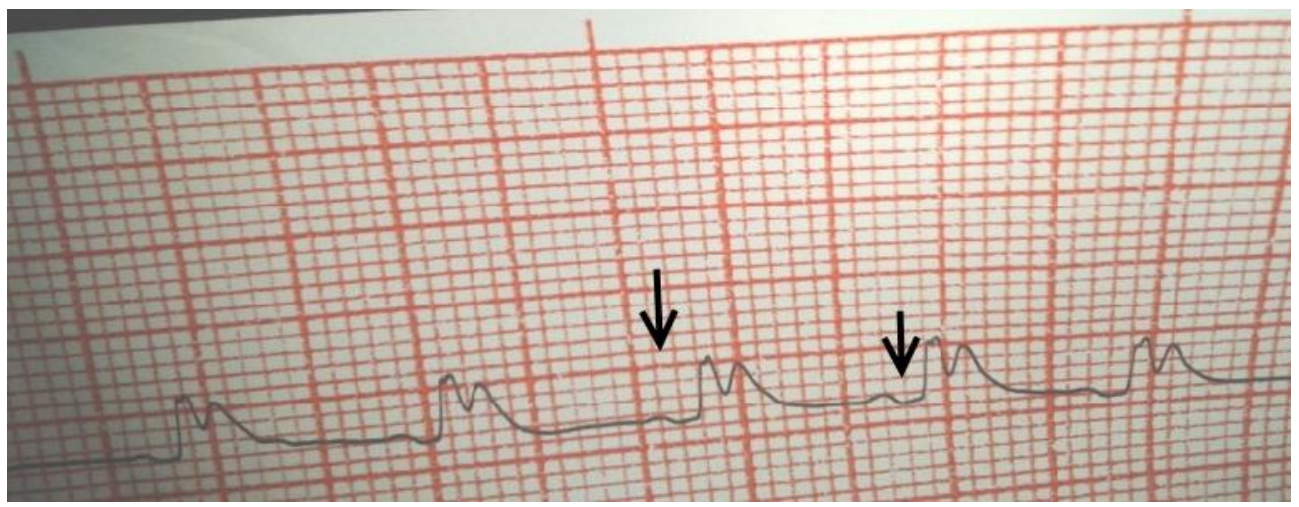

Figure (2): Sinus bradycardia, 210 beat/ minute, PR prolongation and widening of QRS complexes in group II (tested group).

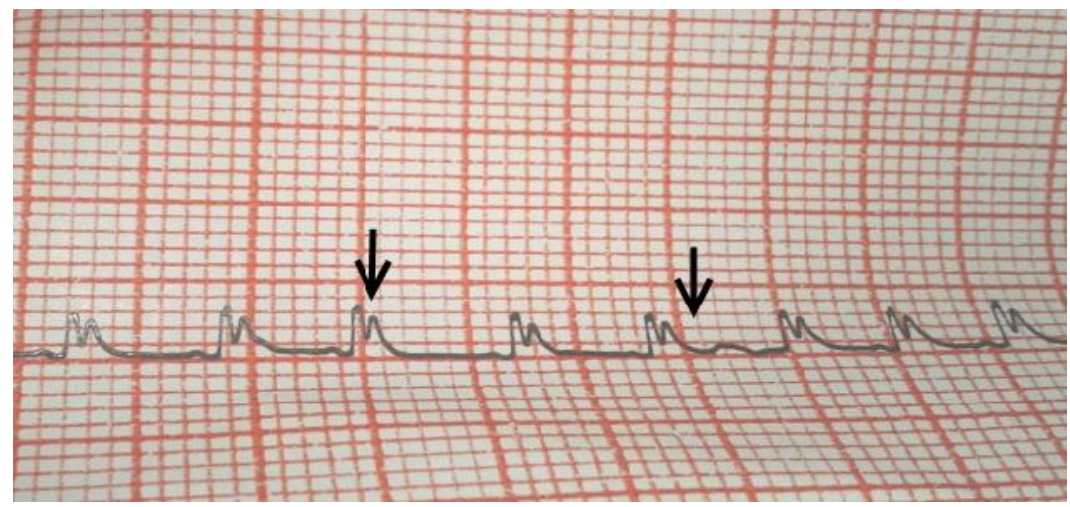

Figure (3): it shows sinus bradycardia 220 beat/ Minute, widening of QRS and prolonged QT intervals in group II (tested group).

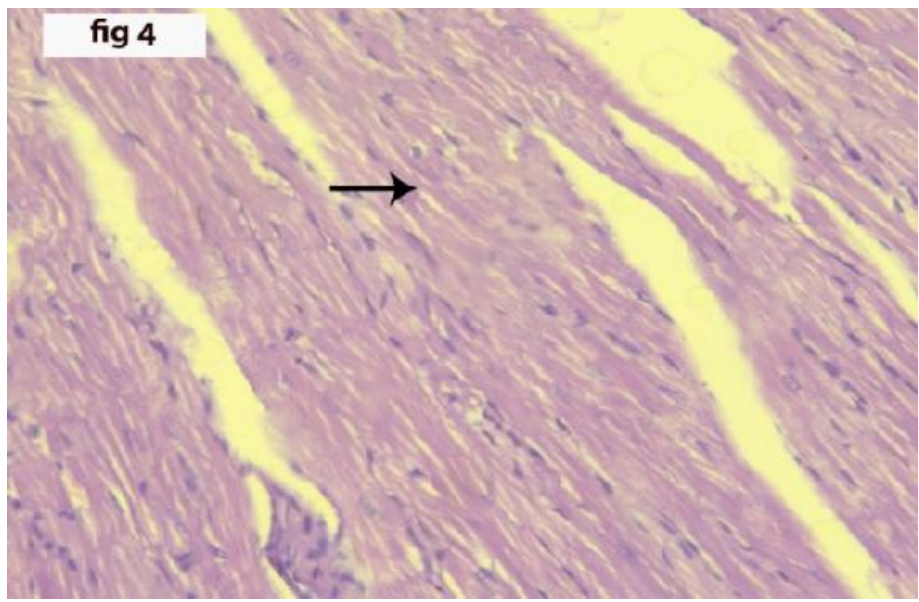

Figure (4): a photomicrograph of a section of the left ventricle of a rat of control group showing regularly arranged cardiac muscle fibers. They appeared branching and anastomosing $(\uparrow)$. 


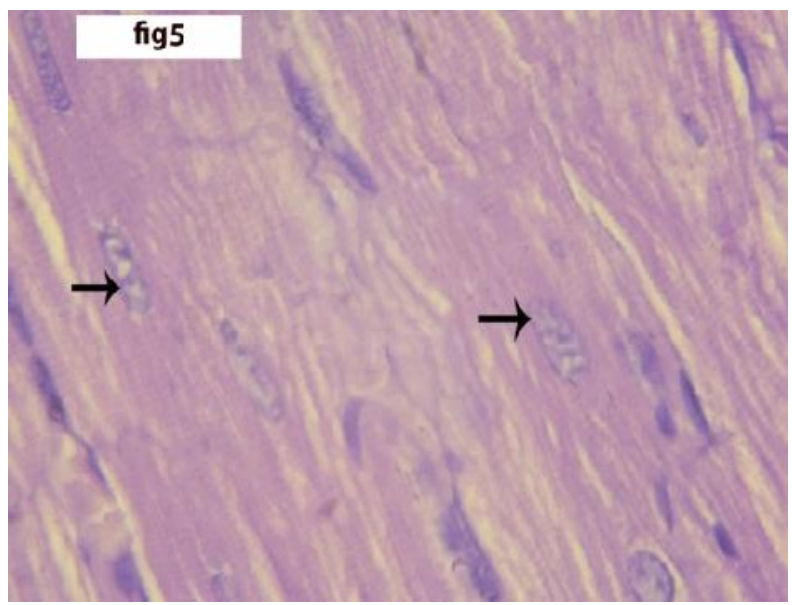

Figure (5): A photomicrograph of a section of the left ventricle of a rat of control group showing longitudinal striated cardiac muscle fibers with acidophilic sarcoplasm and central oval vesicular nuclei $(\uparrow)$.

(H \& E X400)

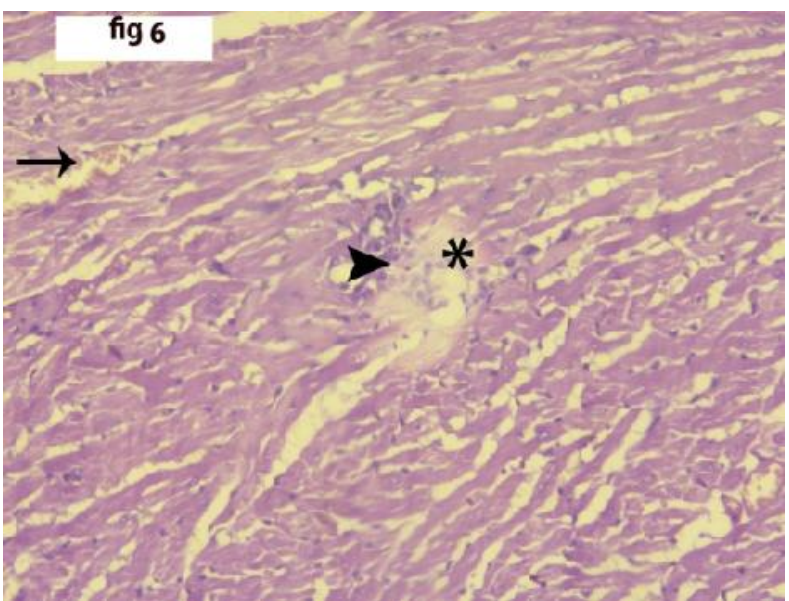

Figure (6): A photomicrograph of a section of the left ventricle of a rat of group II showing an area of loss continuity of cardiac muscle fibers $(*)$. Their sarcoplasms appear pale. Notice the cellular infiltration $(\Delta)$ at this area and the congested a blood vessel $(\uparrow)$.

$($ H \& E X100)

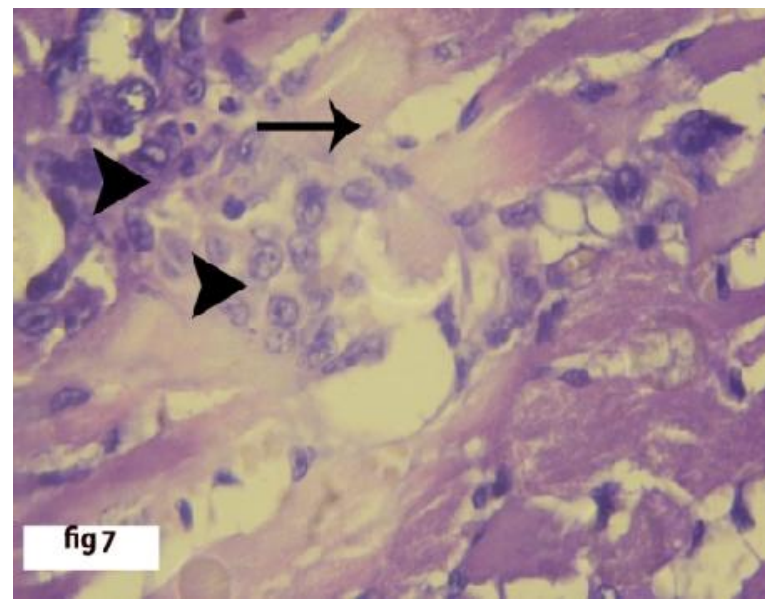

Figure (7): A higher magnification of the previous photo showing mononuclear cellular infiltration $(\Delta)$ where cardiac muscle fibers have pale sarcoplasm $(\uparrow)$ and show loss of continuity.

$($ H \& E X400) 


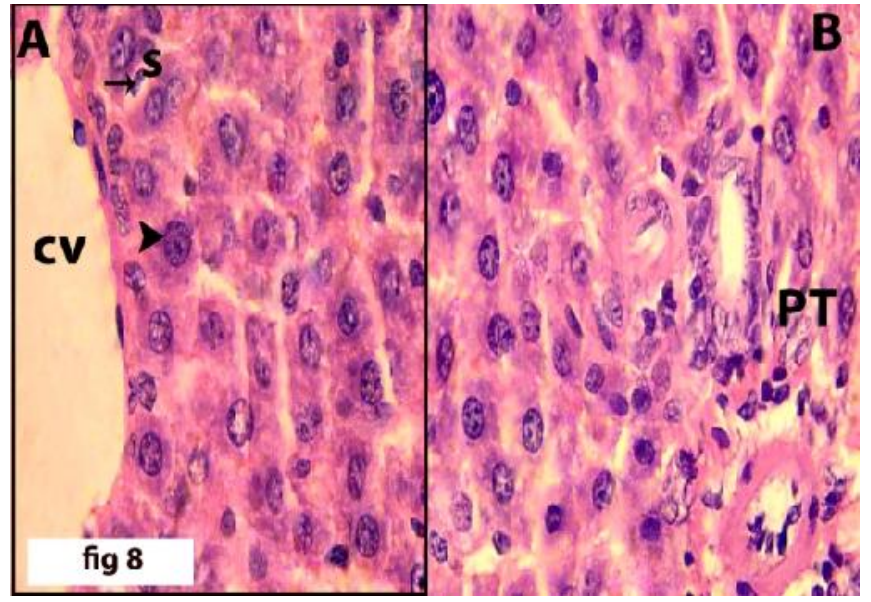

Figure (8): A photomicrograph of a section of a rat liver of control group, showing A:branching and anastomosing cords of hepatocytes around a central vein $(\mathrm{CV})$. Hepatocytes are polygonal with acidophilic granular cytoplasm and central rounded vesicular nuclei $(\Delta)$. Notice blood sinusoids(S) that lined by flat endothelial cells $(\uparrow)$. B: Branches of hepatic artery and bile duct can be seen at the portal tract (PT).

(H \& E X400)

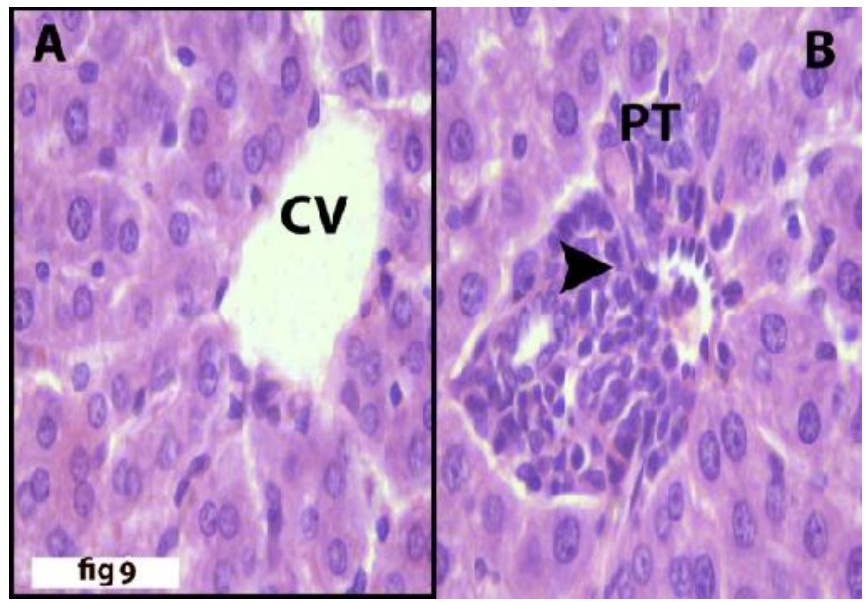

Figure (9): A photomicrograph of a section of a rat liver of group II showing A: cords of hepatocytes arranged around a central vein $(C V)$. B: showing mononuclear cellular infiltration at a portal tract $(\Delta)$.

(H \& E X400)

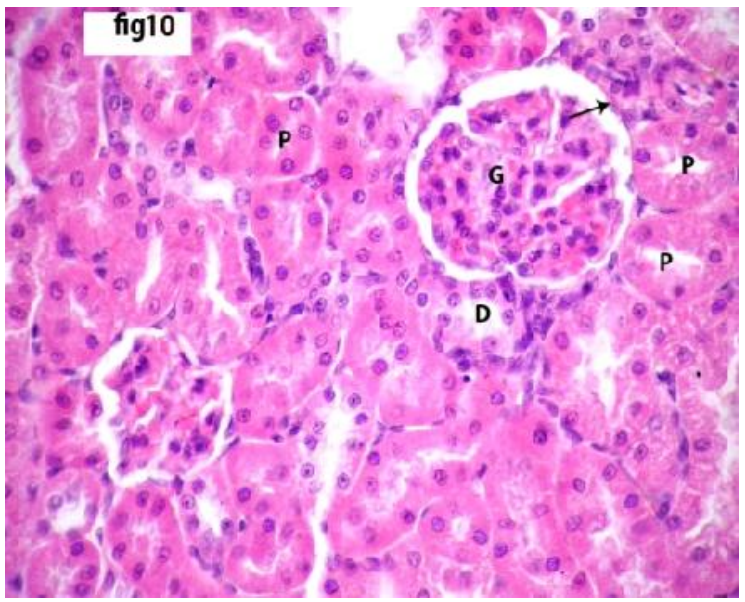

Figure (10): A photomicrograph of a section of a rat kidney cortex of control group showing the glomerulus (G) which appears lobulated and surrounded by distinct Bowman's space. The parietal layer $(\uparrow)$ is lined by flat cells. The P.C.Ts (P) appears lined with pyramidal cells and has narrow lumen. The D.C.Ts (D) appear lined with cubical cells and have wider lumen.

(H \& E x200) 


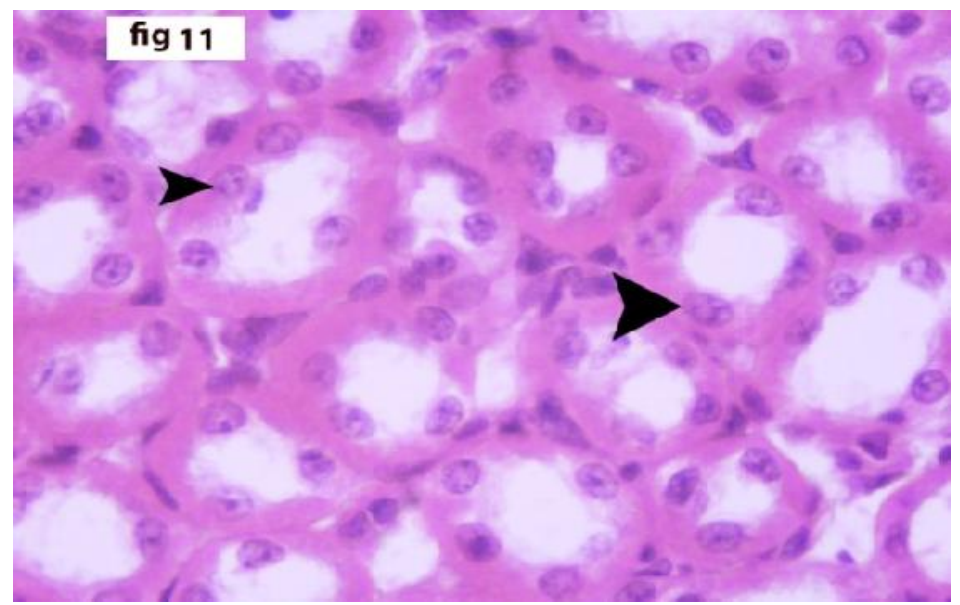

Figure (11): A photomicrograph of a section of a rat kidney medulla of control group showing the collecting tubules which appeared lined by cubical epithelium with clear cytoplasm and rounded central nuclei $(\Delta)$.

(H \& E x400)

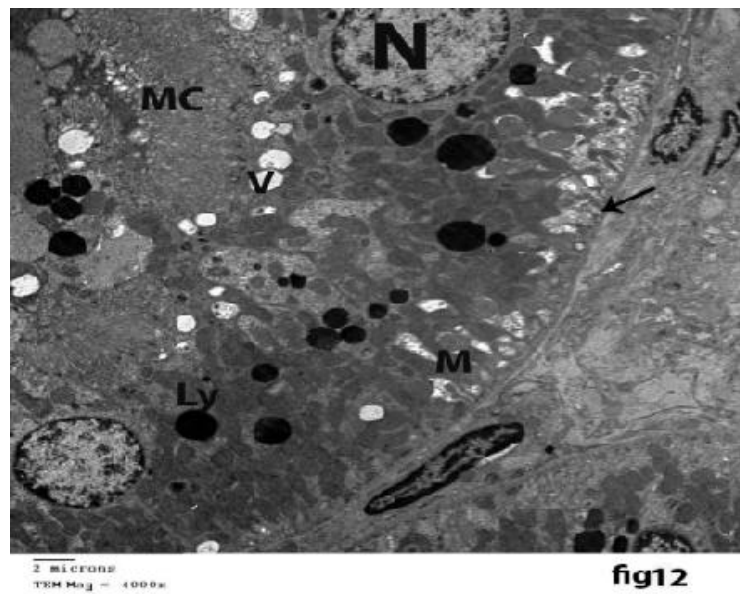

Figure (12): An electron micrograph of a section of a rat kidney cortex of control group showing a part of PCT with two epithelial cells. Notice the prominent microvilli (MC), apical vacuoles (V), euchromatic nuclei (N), mitochondria (M), lysosomes (L) and basal lamina ( $\uparrow)$.

(TEM X4000)

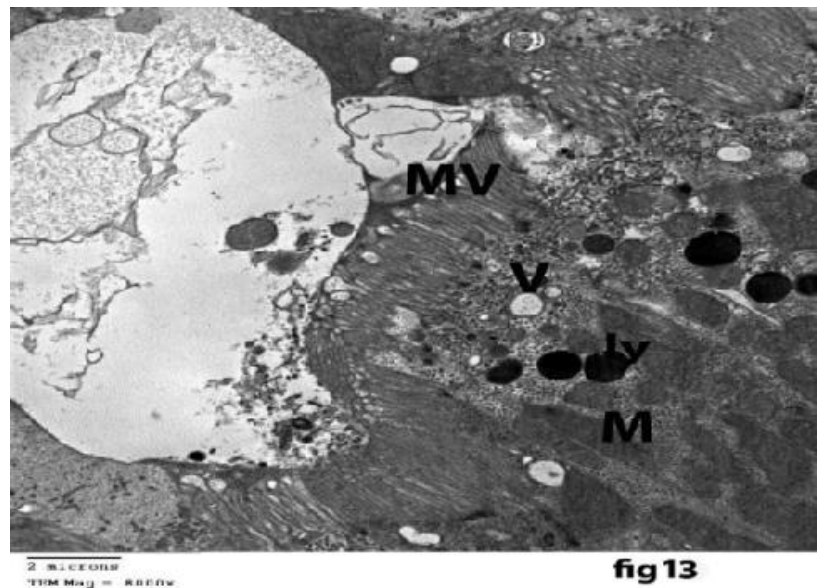

Figure (13): An electron micrograph of a section of a rat kidney cortex of control group showing the apical portion of a cell lining a PCT with prominent apical microvilli (MC). Vacuoles (V), mitochondria (M) and lysosomes (L) can be seen.

(TEM X8000) 


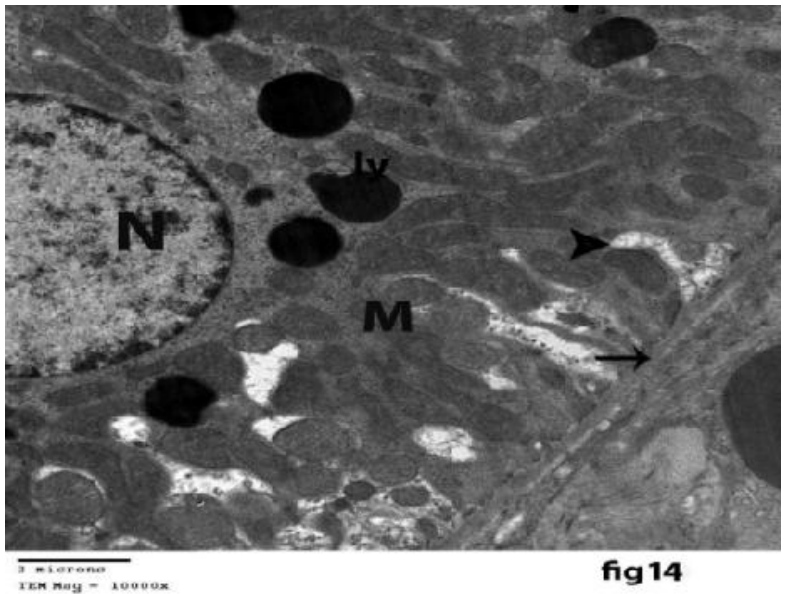

Figure (14): An electron micrograph of a section of a rat kidney cortex of showing the lower portion of a cell lining a PCT with basal infoldings $(\Delta)$, elongated mitochondria $(\mathrm{M})$, lysosomes $(\mathrm{L})$ and basement membrane $(\uparrow)$. Notice euchromatic nucleus $(\mathbf{N})$.

(TEM X10000)

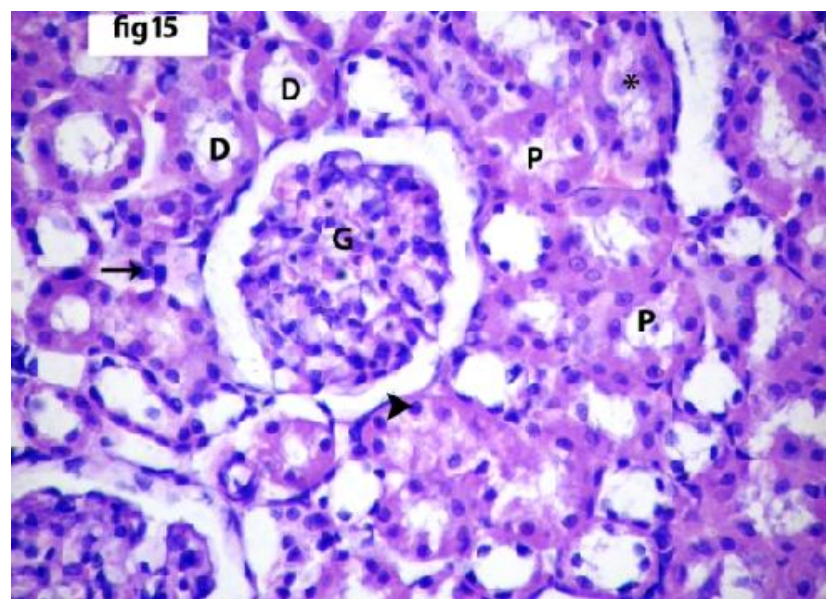

Figure (15): A photomicrograph of a section of a rat kidney cortex of group II showing glomerulus (G). The P.C.Ts (P) and the D.C.Ts (D) show vacuolation of their lining cells. The lining cells of some tubules have pyknotic nuclei $(\Delta)$. Notice the minimal cellular infiltration $(\uparrow)$ and a nucleus in the lumen of a tubule $(*)$.

(H \& E x200)

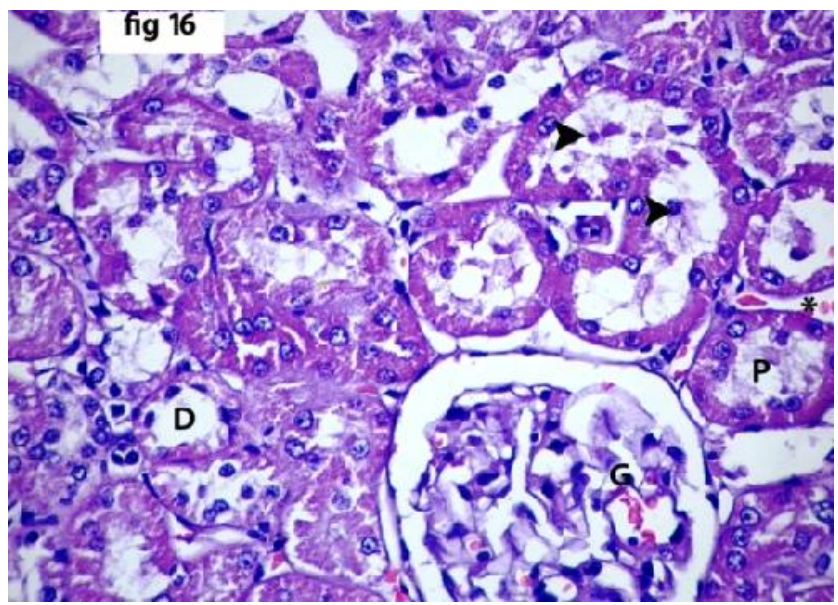

Figure (16): A photomicrograph of a section of a rat kidney cortex of group II. There is marked vacuolation and degeneration of the PCTs (P) and DCTs (D). Desquamation of the tubular epithelial lining is seen inside the lumen (A) of many tubules. Notice RBCs in the peritubular capillaries (*). (G: Glomerulus)

(H \& E x200) 


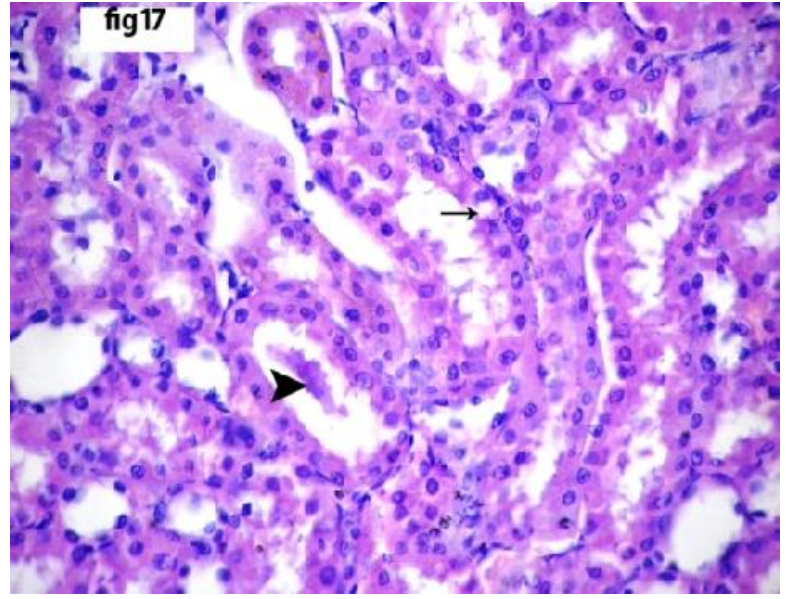

Figure (17): A photomicrograph of a section of a rat kidney medulla of group II showing cellular casts in the lumen of the collecting tubules $(\Delta)$. The cells lining some collecting tubules are vacuolated $(\uparrow)$.

(H \& E x200)

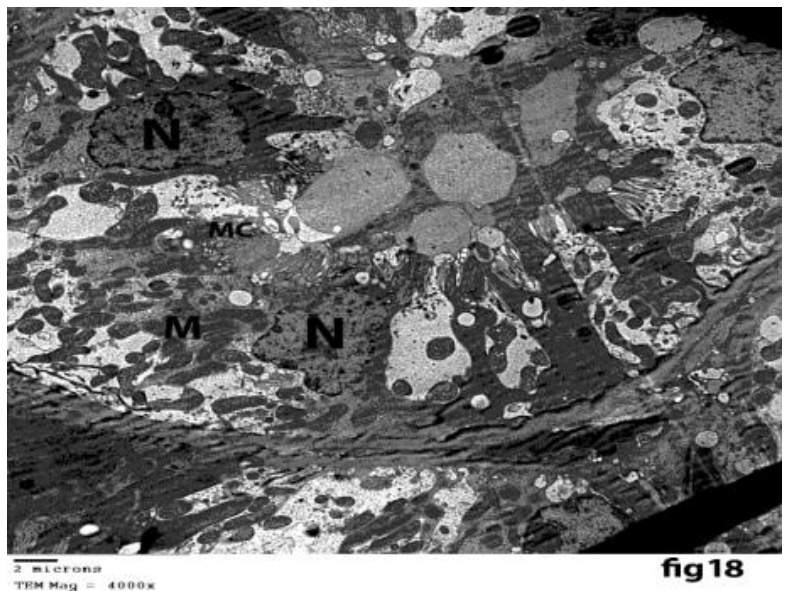

Figure (18): An electron micrograph of a section of a rat kidney cortex of group II showing disfigurement of epithelial lining of a part of a proximal convoluted tubule. Notice the irregular nuclei (N), apical microvilli (MC) and loss of normal arrangement of mitochondria (M).

(TEM X4000)

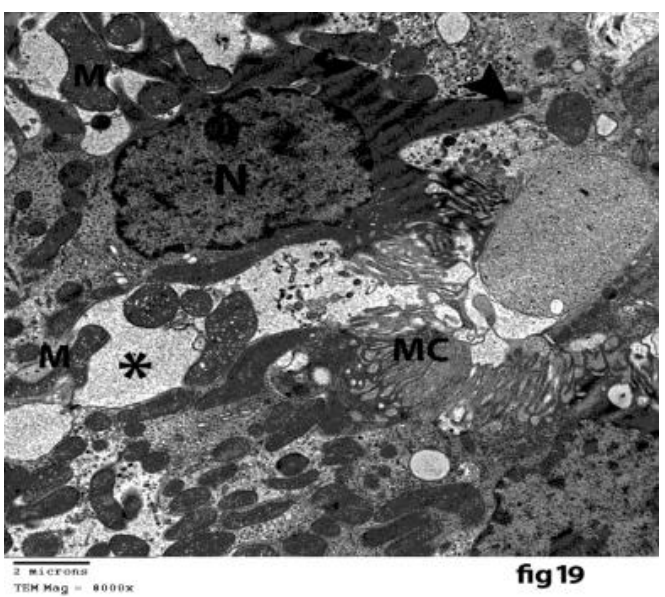

Figure (19): An electron micrograph of a section of a rat kidney cortex of group II showing epithelial lining of a part of a proximal convoluted tubule. Notice an irregular the nucleus (N), mitochondria (M) of abnormal shape, and electron lucent areas of cytoplasm (*). Microvilli (MC) are apparent at certain sites and absent at others ( $\Delta$ ).

(TEM X8000) 


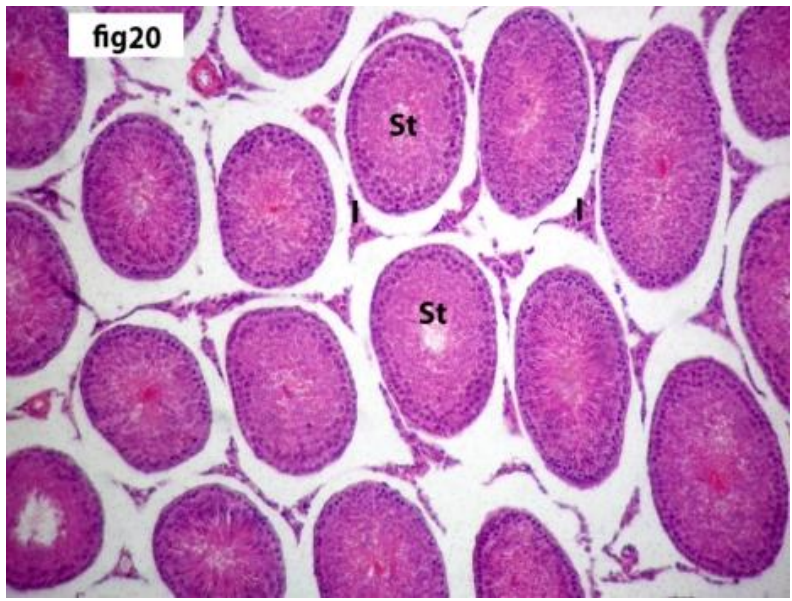

Figure (20): A photomicrograph of a section of a rat testis of control group showing the seminiferous tubules (Sts) lined by several layers of spermatogenic cells and separated by interstitial tissue (I).

(H \& E X100)

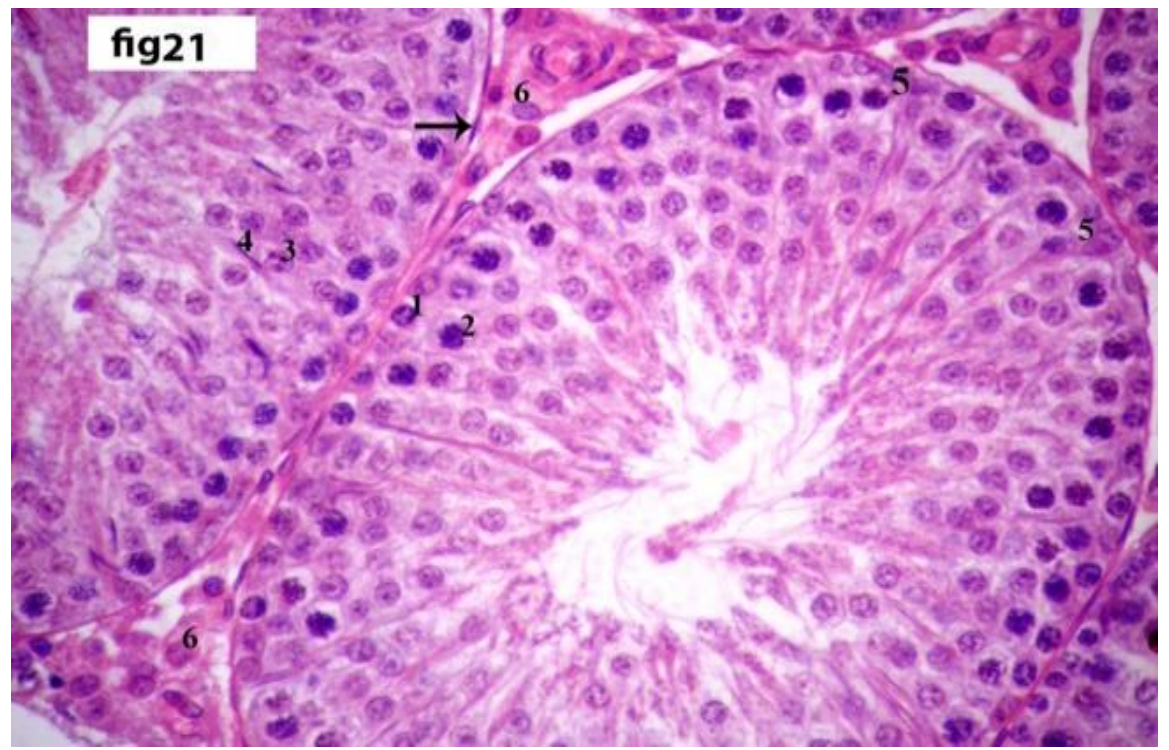

Figure (21): A photomicrograph of a section a of a rat testis of control group showing the lining of Sts including (1) spermatogonia, (2) primary spermatocytes, (3) early spermatids, and (4) late spermatids attached to Sertoli cells (5). Notice myoid cells $(\uparrow)$ and Leydig cells (6) with their vesicular nuclei in the interstitial tissue.

(H \& E X200)

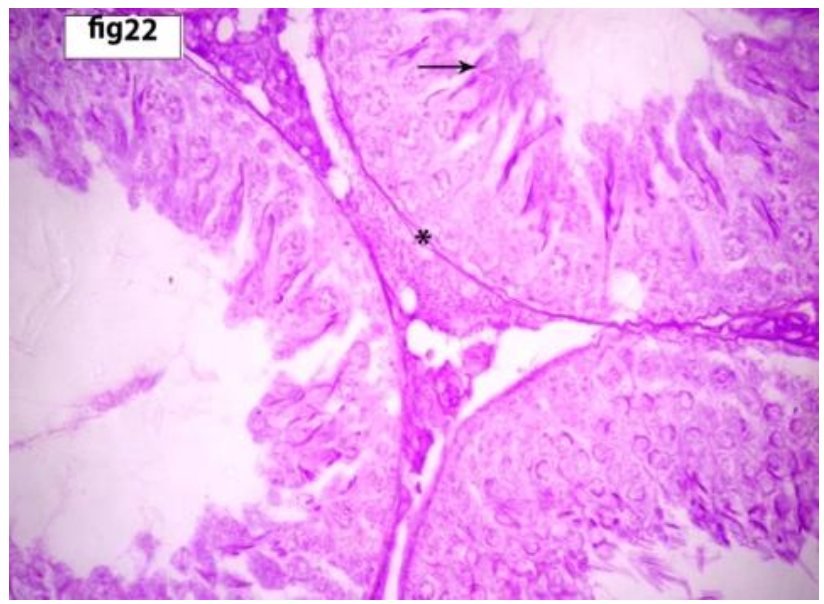

Figure (22): A photomicrograph of a section of a rat testis of control group showing the PAS positive reaction in the basement membrane (*) of seminiferous tubules (St), nucleus of late spermatid $(\uparrow)$ and to less extent in the interstitial tissue.

(PAS X200) 


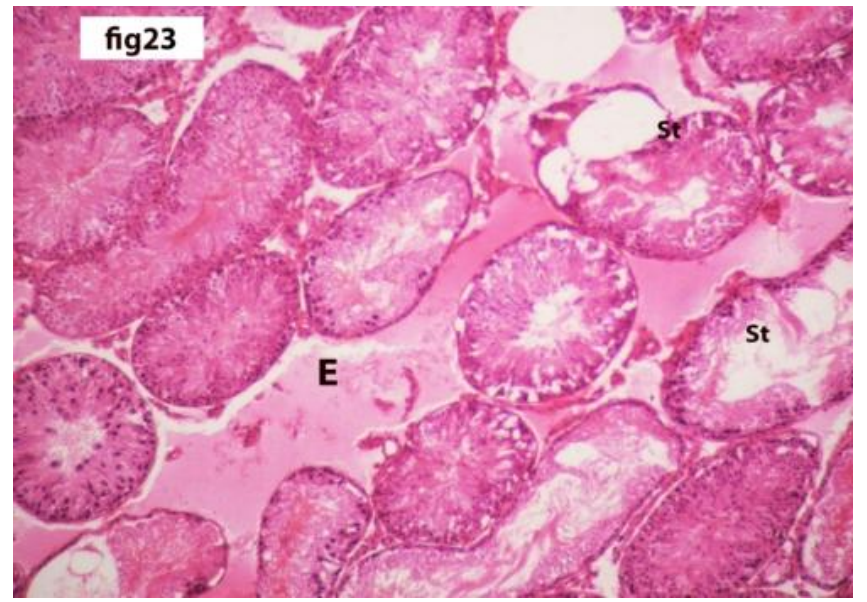

Figure (23): A photomicrograph of a section of a rat testis of group II showing irregular Sts with disorganization of the lining epithelium and exudate in the interstium $(E)$ between the tubules.

(H \& E X100)

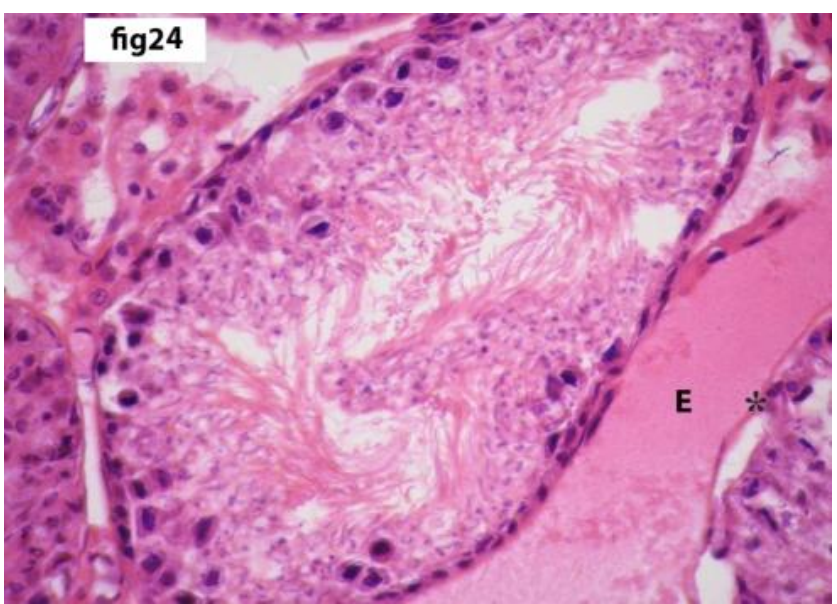

Figure (24): A photomicrograph of a section of a rat testis of group II showing apparent reduction of epithelial lining of a St. Notice separation of the basement membrane of a tubule (*) and exudate (E) between the tubules.

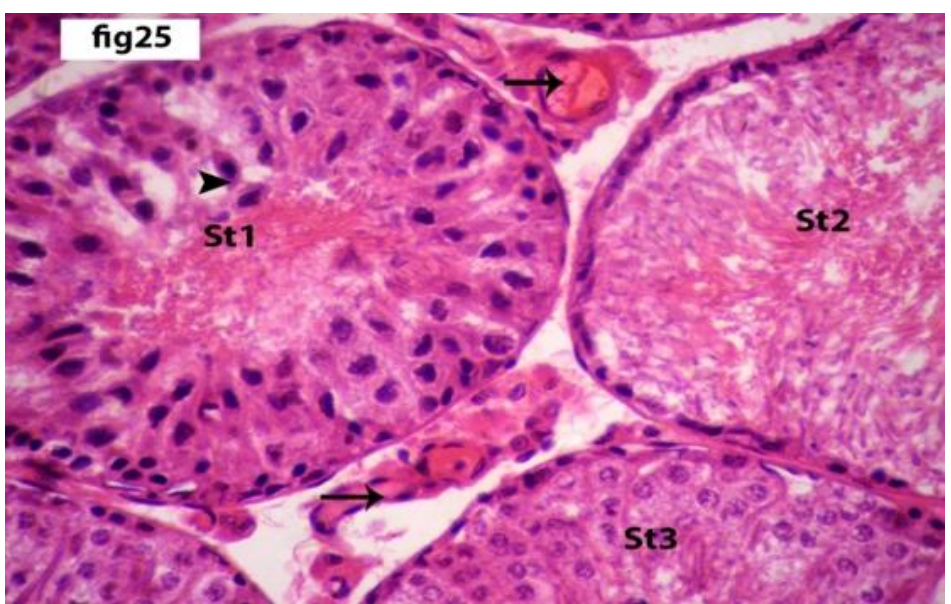

(H \& E X 200)

Figure (25): A photomicrograph of a section of a rat testis of group II showing parts of three Sts. In St1, spermatogenic cells have pyknotic nuclei $(\Delta)$ so that different types of spermatogenic cells can't be identified. Apparent reduction of epithelial lining in St2and almost normal epithelial lining in St3 are detected. Notice the congested blood vessels $(\uparrow)$.

(H \& E X200) 


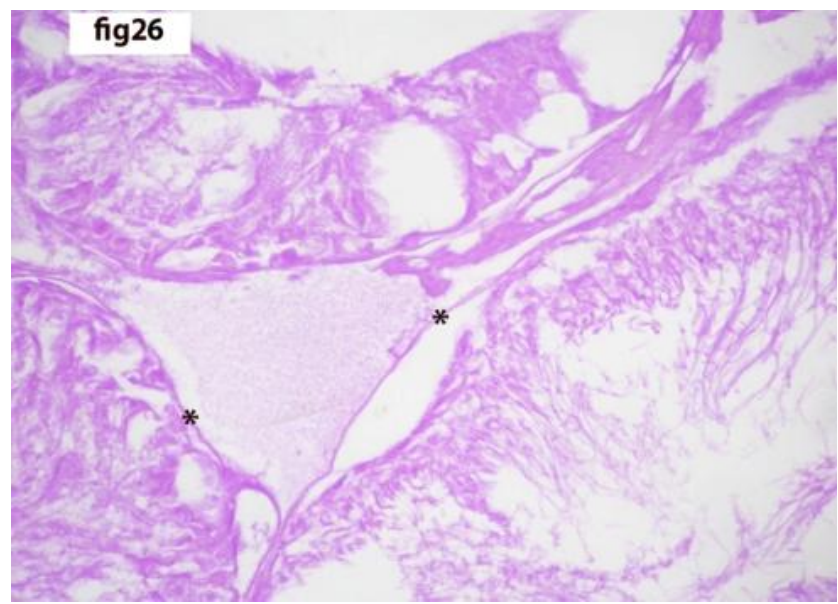

Figure (26): A photomicrograph of a section of a rat testis of group II showing apparent decrease of the PAS positive reaction in the basement membrane of tubules (*).

(PAS X200)

\section{Discussion}

Paraphenylene-diamine (PPD) is a synthetic compound that is widely used as a hair dye. The cosmetic trade in oxidizing hair dyes uses PPD; it is also commonly used to intensify the color of henna. PPD is also used in fur, dark cosmetics and temporary tattoo. In-addition it is also used in; photochemical measurements, manufacturing of tire cords textiles, leather and photographic developer. In USA, about one third of the adult women use PPD containing hair dyes. Currently, PPD is present in more than 1000 hair dye formulations marketed all over the world (Stanely et al., 2005). PPD poisoning, although a rare form of intoxication in the West, is fairly common in some parts of the world such as East Africa, Indian subcontinent, and Middle East countries (Kumar et al., 2012).

Among the more common effects of this poison are edema of the neck, airway obstruction, gastritis, rhabdomyolysis and acute renal failure. There were some reported cases suffered from systemic manifestations following repeated dermal exposure of Henna and PPD contain hair dyes as reported by Hamdouk et al., (2011) .Till today there is no specific antidote for it. Unless identified early and managed aggressively, mortality rates will be high (Jain et al., 2012).

As the largest organ of the body, the skin performs multiple critical functions, such as serving as the primary barrier to the external environment. For this reason, the skin is often exposed to potentially hazardous agents, including chemicals, which may contribute to the onset of a spectrum of adverse health effects ranging from localized damage to systemic toxicity (NIOSH, 2009). Few studies investigated the dermal absorption potential of PPD in humans and animals. It is found that, the dermal absorption or the percutaneous penetration rate of PPD in cosmetic hair dyes has under exposure conditions mimicked the intended-use conditions for such hair dyes (Steiling et al., 2001). In fact, few survey results indicated that in the U.S., $42 \%$ of women and $25 \%$ of men use hair dyes. Therefore, Rosenkranz et al., (2007) recorded that, the use of dyes to alter the coloration of a human's hair represents a considerable added degree of the health risk.

The present study was conducted to investigate biochemical and histological impact of skin, cardiac, renal, hepatic, and testes, induced by repeated dermal exposure to PPD on adult male Albino rats.

The present study showed that there was significant increase of cardiac biochemical markers CPKMB in tested group in comparison to control group. Moreover, there were significant decreases of heart rate as well as significant prolongation of PR, QRS and QT intervals among tested group when compared to control group. This is in accordance with Singh et al., (2008) who investigated some biochemical markers of myocardial damage in a case of acute PPD toxicity. They recorded that, there was elevated CPK-MB serum level and positive c-troponin. Moreover, electrocardiographic strips showed that there was Right bundle branch block, supraventricular and ventricular ectopics. Singh et al. (2009) added that besides elevated cardiac biomarkers of acute PPD toxicity there was ST segment elevation and T wave inversion. In-addition, Mannem et al. (2009) reported that prolonged elevation of CPK-MB could be due to cardiomyopathy, cardiac hypertrophy and myocarditis as recorded in cases collected in their study. Shalaby et., al. (2010) investigated the cardiotoxic effects of PPD in a retrospective study of over 7 years (20012007) on 25 cases with acute PPD intoxication admitted to the Poison Control Center, Ain Shams University Hospitals, Cairo, Egypt. They reported that, $16 \%$ of the 
patients died due to ventricular arrhythmia. Jain et al. (2012) recoded that there were myocarditis among 15\% of total cases of paraphenylenediamine poisoning based on clinical and investigational profile. These included some ECG changes as extrasystols, inverted $\mathrm{T}$ wave and Heart block as well as elevation of CPK-MB fraction.

Balasubramanian et al.(2013) added that, myocarditis occurs in nearly $1 / 6$ th of the patients examined in their study who were consuming the dye, with nearly $1 / 10^{\text {th }}$ among these cases developed life threatening ventricular tachycardia/fibrillation. They also recorded that, the cardiac manifestation seems to be directly related to the amount of the hair dye consumed. Cardiac manifestation may present as weakness, dyspnea on exertion, chest pain, palpitation, syncope. ECG changes included bradycardia, $\mathrm{T}$ wave inversion, ST segment elevation or depression, QRS widening, right and left bundle branch blocks, atrial and ventricular premature complexes, atrial fibrillation, and ventricular tachyarrhythmia. Echocardiography may show ventricular hypokinesia and decreased left ventricular ejection fraction.

Besides, in this study, histological examination of $\mathrm{H} \& \mathrm{E}$ stained left ventricular sections of the heart belong to animals in group II showed focal areas of loss of continuity of cardiac muscle fiber with pale sarcoplasm and mononuclear cellular infiltration. Jasmin and Gareau (1961) recorded that there were multiple foci of myocardial degeneration together with mononuclear cellular infiltration after subcutaneous injection of 3 $\mathrm{mg} / \mathrm{kg}$ PPD for 21 days.In-addition, Abd-ElZaher et al. (2012) added that, sub-chronic dermal exposure to PPD induced myocarditis. They explained that, repeated PPD dermal exposure induced chronic inflammatory cardiac histological changes correlated with the elevation of both CPK-MB and LDH biomarkers.

Moreover, Chaudhary et al. (2013) mentioned that there were few reports about development of myocarditis and cardiac arrhythmias in case of PPD poisoning. Moreover, PPD toxicity depends on the rate of metabolic clearance. This rate may vary from person to another. Hence the liability to the chemical-induced damage differs (Bharali et al., 2012).

In the present study, PPD induced significant elevation of liver enzymes both ALT and AST in tested animals (group II) when compared to control animals (group I). In other human studies, a 27 years-old Japanese man with no history of liver disease was admitted to the hospital due to liver abnormalities. The patient was diagnosed with drug-induced hepatitis, as the three episodes of hepatitis occurred just after repeated use of hair dye. After cessation of the hair dye use, abnormal liver function tests and that were improved within the normal ranges (Tokumoto et al., 2004). Although, hair dyes contain various hepatotoxic compounds, hair dye is not known to cause drug-induced hepatitis; Abd-ElZaher et al. (2012) reported that, PPD induced significant elevation of liver enzymes with chronic inflammation of the liver in a dose dependent manner. Moreover, Prabhakar, and Amalakar (2012) reported some cases of acute hair dye intoxications developed hepatic dysfunction and this was evident by elevated ALT and AST serum levels.

In the present work, histological examination of $\mathrm{H}$ \& $\mathrm{E}$ stained sections of rat liver of group II, mononuclear cellular infiltration could be detected in someportal tracts. This in accordance with Yoshio et al. (2003) who stated that, PPD mediated hepatotoxicity and that was evident from histo-pathological observation (inflammation of the portal tract) and sharp rises in the serum biomarkers indicating liver injury which was dose dependent manner. Moreover, this was in agreement with Bharali and Dutta(2009) who observed cellular infiltration at the portal areas. They explained that, although a little fraction of PPD is absorbed through skin, it has a long plasma half-life. They suggested that PPD affected the vascular endothelium which leads to extravasation depending on some chemotactic factors like TNF $\alpha$ and IL8.

Moreover, the present study reported that there was significant elevation of kidney function testes. There was significant elevation of serum creatinine, BUN and $\mathrm{K}^{+}$level. This was in parallel with a study of Saad et al. (2000) who stated that, elevated serum creatinine and BUN are merely associated with abnormal renal function, more specifically with reduced glomerular filtration rate. Ram et al. (2007) reported acute renal failure, leukocytosis, and anemia secondary to hemolysis, hemoglobinemia and hemoglobinuria in cases admitted to Department of Nephrology, Nizam's Institute of Medical Sciences due to PPD toxicity during 2002 to 2006. They added that those suffered from acute renal failure were not more that $1 \%$ of all patients which was proved by renal biopsy done for them and reviled acute tubular necrosis. Recovery occurred in $70 \%$ of them after receiving 2-6 hemodialysis sessions.

However, Sampathkumar et al. (2007) recorded that, rhabdomyolysis is the main cause of acute renal failure and the morbidity and mortality are high once renal failure develops. Hypovolemia and the direct toxic effects of PPD or its metabolites on the kidneys also contribute to acute tubular necrosis that had been described in PPD poisoning.

Wadaan (2006) investigated chronic PPD exposure on rats which suffered from renal cell necrosis following exposure to PPD chronic application to the 
skin can lead to glomerular injury. Gude et al. (2012) reported a case of acute PPD consumer as suicidal attempt, they found that her urine was cola colored. Investigations obtained revealed hypocalcaemia (corrected calcium $=7.2 \mathrm{mg} / \mathrm{dl}$ ) with normal sodium, potassium, creatinine, and phosphorus values.

In this work, histological examination of $\mathrm{H} \& \mathrm{E}$ stained kidney sections of group II animals showed damaging effect particularly affecting the epithelial lining of proximal convoluted tubules. This effect included vacuolation of cytoplasm, pyknotic nuclei, and even desqumation of epithelium into the lumens. This agreed with Hamdouk et al. (2011) and Bharali et al. (2012) who observed tubular lesion in the form of tubular atrophy and hyper-cellularity of glomerulous. Moreover, Bai et al (2012) recorded that, PPD inhibited proliferation of a proximal tubular cell (PTC) line derived from normal kidney (HK-2). They also explained that to the increased level of apoptosis of HK-2 cells and the mRNA caspase- 3 .

In-addition, electron microscopic examination of the kidney sections of group II animals showed areas of loss of apical microvilli of the epithelium lining of proximal convoluted tubules. Loss of normal pattern of mitochondria, which appeared irregular and of abnormal shape. Cataldo et al. (2010) mentionedthat mitochondrial function is related both to mitochondrial shape and to their intracellular distribution. They added changes in mitochondrial morphology and distribution appear to be closely linked to cellular events, such as aging, and apoptosis. These findings could explain deterioration of renal function in this study.

Soni et al. (2009) attributed the effect of PPD on the kidney to a direct tubular toxicity. Chen et al. (2010) found that PPD induced cytotoxicity and reactive oxygen species (ROS) generation which are considered as a trigger of the oxidative stress. Hummdi, (2012) explained that for an oxidation product of PPD metabolites (quinonediamine) was highly nephrotoxic. Elyoussoufi et al. (2013) proved that PPD induced an increase of malondialdehyde level which estimates the lipid peroxidation level. They added that lipid peroxidation is increased by ROS which cause damage to cells by oxidizing lipids in the cell membrane or by attacking DNA directly. They explained that lipid peroxidation affects the physical stability of the membranes, resulting in altered calcium homeostasis, activation of endonucleases and oxidative damage to DNA.

In this study, minimal mononuclear cellular infiltration in the renal interstitium could be seen in some section of kidney of group II. Bharali et al. (2012) reported that the increased heme protein accumulation in PPD treated rats might trigger the up-regulation of monocyte chemo-attractive protein 1 (MCP1) in the kidney tubules via nuclear factor-kB (NF-kB).

The histological findings in testes of animals in group II of the present study included reduction of epithelial lining and spermatogenic cells had pyknotic. Moreover, there were sloughing of epithelium of seminiferous tubules with presence of giant cells and interstitial exudate. This in accordance with Picardo et al. (1992) who examined testicular sections of rats exposed to PPD they detected that, there was testicular interstitial exudate in some sections of the testis of this study.

These were in agreement with a study for Bharali and Dutta, (2012) who investigated the reproductive toxicity of PPD in male rats after subchronic topical application of different doses $(0,1,2$ and $3 \mathrm{mg} / \mathrm{kg} / \mathrm{day}$ ) of PPD. They also attributed these changes to the elevation of lipid peroxidation product in the testicular tissue indicated the potential oxidative stress that induced cellular apoptosis. The male albino rats exhibited significant decrease in the total sperm count with consistent decrease in the testicular weight.

Chen et al. (2010) attributed the testicular effect caused by para-phenylenediamine exposure to oxidative stress which in turn causes activation of certain caspases.

The present study reported that, examination of $\mathrm{H} \& \mathrm{E}$ stained sections of exposed skin of tested animals in group II didn't reveal any histological changes as compared to control group I. This might be explained by the fact that PPD cause $s$ contact dermatitis if the individual is susceptible (Felali et al., 2006). Hueber et al. (2004) reported similar dermal absorption values, of $2.44 \%$ and $3.39 \%$ in vitro, in human and pig skin, respectively. These results indicate that the chemical is absorbed to a lesser extent from hair-dye formulations than from the neat chemical, presumably because lower amounts of PPD are applied under typical use conditions.

Lind et al., (2005) and Bharali and Dutta, (2009) investigated the dermal exposure of hairdressers to oxidative hair dyes. The studies focused on hair dye residues on the hands of hairdressers after hair dyeing with or without gloves, as well as hand exposure during the cutting of dyed hair. Meanwhile, the given study did not investigate the systemic exposure, the significance in terms of a human health risk of small residues detected on the hair-dresser's hand is uncertain. Overall, the occupational systemic exposure of hairdressers to hair dye ingredients remains virtually unknown.

\section{Conclusion}

Paraphenylene-diamine (PPD) is a synthetic compound that is widely used as a hair dye and cause various systemic manifestations either on acute or chronic 
exposure. The present work revealed that repeated topical application to PPD for 90 days in a dose of $10 \mathrm{mg} . \mathrm{kg}$ caused significant elevation of cardiac markers (CPK$\mathrm{MB}$ ), significant elevation of both hepatic enzymes (AST and ALT) and renal biomarkers (S. creat., BUN and $\mathrm{K}^{+}$). Moreover, the study showed significant ECG changes as bradycardia, prolonged PR, QRS and QT intervals with evident ischemia in the form of elevated ST segment in $70 \%$ of tested animals. Moreover, histological changes were evident on examination of cardiac, hepatic and renal tissues of tested animals. Thus repeated dermal exposure could induce various systemic affection.

\section{Recommendation}

- PPD handlers such as hair dresser, textile manufacturing workers, and chronic tattoo users should be subjected to serial biochemical follow up parameters as cardiac, hepatic, renal, and hormonal workout.

- The above mentioned risk group populations should have protective measures decreasing chronic hazardous of PPD as protective gloves, overalls and masks for those working in photographing manufacturing.

- Further studies of chronic PPD systemic toxicities including gentotoxicities advised to be accomplishes as well as investigating protective drugs and agents ameliorating such toxicities.

\section{References}

Abd-ElZaher MA, Fawzy I A, Ahmed H A et al., (2012): Some toxicological health hazards associated with subchronic dermal exposure to paraphenylene-diamine (PPD): An experimental study. Egyptian Journal of Forensic Sciences 2, 105-111.

Bai YH, Peng YM, and Yin WQ et al., (2012): pAminophenol and p-paraphenylenediamine induce injury and apoptosis of human HK-2 proximal tubular epithelial cells. J. Nephrol; 25(4):481-9.

Balasubramanian D, Singh H, Thangaraju $P$ et al., (2013): Cardiac Arrest: Uncommon Toxicity. In: Hair Dye Poisoning. Rational Pharmacother. Res. 1 (1): 72-74.

Bancroft JD and Gamble M. (2007): Theory and Practice of histological techniques, 6th edition London Churchill Livingstone.

Bancroft JD and Cook HC (1994): Manual of histological techniques and their diagnostic application. London: Churchill Livingstone;
Bharali MK and, Dutta K (2012): “Testicular toxicity of para-phenylenediamine after subchronic topical application in rat". Int J Environ Health Res; 22(3):270-8.

Bharali MK, Basumatary R, Rahman T et al., (2012): Repeated Topical Application of paraPhenylenediamine Induces Renal Histopathological Changes in Rats. Toxicol Int. 19(2):132-7.

Bharali MK and Dutta K (2009): Hepatic histopathological abnormalities in rats treated with paraphenylene-diamine (PPD). J.Pharmacol.Toxicol, 4(6):221-228

Cataldo A M, McPhie DL, Lange NT et., al. (2010): Abnormalities in Mitochondrial Structure in Cells from Patients with Bipolar Disorder. Am. J. Pathol; 177(2): 575-585.

Chaudhary SC, Sawlani KK and Singh K (2013): Paraphenylenediamine poisoning. Niger J Clin Pract; 16: 258-9.

Chen SC, Chen CH, and Tioh YL et al., (2010): Paraphenylenediamine induced DNA damage and apoptosis through oxidative stress and enhanced caspase- 8 and -9 activities in Mardin- Darby canine kidney cells. Toxicol. In Vitro; 24:1197202.

Elyoussoufi Z, Habti N, Mounaji K et al., (2013): Induction of oxidative stress and apoptosis in human neutrophils by p-phenylenediamine. J. Toxicol. Environ. Health Sci; 5(8):142-149.

Filali A, Semlali I, Ottaviano V, et al., (2006): A retrospective study of acute systemic poisoning of paraphenylenediamine (occidental takawt) in Morocco. AFrJTrade CAM; 3(1):142-9.

Gouma E, Y Simos Y, Verginadis I et al., (2011): A simple procedure for estimation of total body surface area and determination of a new value of Meeh's constant in rats. Lab Anim 2012 46: 40.

Gude D, Bansal D P, Ambegaonkar R et al., (2012): Paraphenylenediamine: Blackening more than just hair. J. Res. Med. Sci; 17:584-6.

Hamdouk M, Abdelraheem M, Taha A et al., (2011): The association between prolonged occupational exposure to paraphenylenediamine (hair -dye) and renal impairment. AJNT; 4(1):21-5

Hueber B F, Nohynek GJ, Meuling WJA et al., (2004): Human systemic exposure to a [14C]-paraphenylenediamine-containing oxidative hair dye and correlation with in vitro percutaneous absorption in human or pig skin. Food Chem Toxicol 42(8):1227-1236.

Hummdi LA. (2012): Histopathological Alterations in Renal Tubules of Female Rats Topically Treated 
with Paraphenylen Diamine. World Appl. Sci. J; 16:376-88.

Jain PK, Navneet A., Sharma A.K. et al. (2011): Prospective study of ingestional hair dye poisoning in Northern India (PROHINA). J. Clin. Med. Res. 3(1):9-19.

Jain PK, Sharma AK, Agarwal N et al., (2012): A prospective clinical study of myocarditis in cases of paraphenylenediamine (hair dye) poisoning in Northern India. Journal of Clinical Medicine Research; 4(7): 106-16.

Jasmin G. and Gareau (1961): Histological Study of Muscles lesions produced by Paraphenylendiamine in rats. Br. J. ExpPathol; 42(6): 592-596.

Kallei H, Chelly H, Dammak H et al., (2005): Clinical manifestation of systemic paraphenylenediamine intoxication. J Nephrol; 18:308-11.

Kumar AS, Talari K and Dutta TK (2012): Super vasomol hair dye poisoning. Toxicol Int; 19:778.

Lind ML, Boman A, Sollenberg J, et al., (2005): Occupational dermal exposure to permanent hair dye among hairdressers. Ann. Occup. Hyg; 49:473-80.

Mannem SR, Praveen K N, Gupta V et al., (2009): Elevated CK-MB without myocardial infarction. Scientific Medicine; 1(2)

NIOSH, National Institute for Occupational Safety and Health (2009): NIOSH Skin Notation (SK) Profile. Cited In: www.cdc.gov/niosh

Picardo MC, ZompettaC MarcheseC et al., (1992): Paraphenylenediamine, a contact allergen, induces oxidative stress and ICAM-1 expression in human keratinocytes. Br. J. Dermatol., 126(5): 450-455.

Prabhakar YVS and Amalakar K (2012): Hair dye poisoning: A report of three cases. Journal of Dr. NTR. University of Health and Science; 1. (1): 46-48.

Ram R, Swarnalatha G, Prasad N et al., (2007): "Paraphenylenediamine ingestion: An uncommon cause of acute renal failure". J. of Postgraduate medicine; 53: 3: 181-18.

Rauscher GH, Shore D and Sandler DP (2004): Hair dye use and risk of adult acute leukemia. Am. J. Epidemiol., 160: 19-25

Rosenkranz HS, Cunningham SL, Mermelstein R et al., (2007): The challenge of testing chemicals for potential carcinogenicity using multiple short term assays: an analysis of a proposed test battery for hair dyes. Mutat. Res; 633:55-66.

Saad HA, Mousa HM, and Ali BH (2000): Some toxicological observations on paraphenylenediamine (Hair dye) in rats and chickens. Pakistan J. Biol. Sci; 3(6):953-956.

Sampathkumar K, Sooraj YS, Ajeshkumar R P et al., (2007): Rhabdomyolysis due to hair dye poisoning: An emerging threat. Indian Journal of Critical Care Medicine; 11, 4: 212-214.

SCCP, Scientific Committee on Consumer Products (2006): Opinion on p-Phenylenediamine. In: the $9^{\text {th }}$ plenary meeting of 10 October 2006 . Health and consumer protection directorate-general. European Commission. Cited in: http://ec.europa.eu/health/ph_risk/committees/0 4_sccp/docs/sccp_o_069.pdf

Shalaby SA, Elmasry MK, Abd- Elrahman AE et al., (2010): Clinical profile of acute paraphenylenediamine intoxication in Egypt. Toxicol. Ind. Health; 26: 81.

Singh AP, Jatav OP, and Dudani M (2009): Myocarditis in hair dye poisoning. Indian Heart J; 61(3):306-7.

Singh N, Jatav OP, Gupta RK et al., (2008): Myocardial damage in hair dye poisoning-an uncommon presentation. J. Assoc. Physicians India; 56: 463-4.

Soni SS, Nagarik A P, Dinaker M et al., (2009): Systemic toxicity of paraphenylenediamine. Indian Journal of Medical Sciences; 63(4):164-6.

Stanely LA, Skare JA, and Doyle E et al., (2005): Lack of evidence for metabolism of pphenylenediamine by human hepatic cytochrome p450 enzymes. Toxicolog; 210:147-57.

Steiling W, Kreutz J, and Hofer H (2001): Percutaneous penetration/dermal absorption of hair dyes in vitro. Toxicol Vitro 15(4-5):565-570.

Tokumoto Y, Horiike N, Onji M et al., (2004): Druginduced hepatitis due to repeated use of hair dye. Third department of Medicine. Endoscopy Center; Ehime University School of Medicine, Ehime.

Wadaan MAM (2006): Blood chemistry of Domestic Rabbits exposed to an oxidative hair dye. Int. J. Pharm; 2(4):431-434.

Yoshio T, Horiike N, Onji M et al., (2003): Drug induced hepatitis due to repeated use of hair dye. Internal Med, 42, pp. 1104-1166. 
الملخص العربى

تعرض الجلد المتكررللبارافينيليين دياميين يسبب تغيرات كيميائية و هستولوجية لأجهزة ذكور الجرذان البيضاء البالغة

هند الهلالي' و صفاء محمد شاكر r

إن البارافينيليين دياميين (ب ب د) هو مركب صناعي يستخدم على نطاق واسع لصبغ الشعر. و وف هذ هذه الدراسة إلى التحق من الآثار

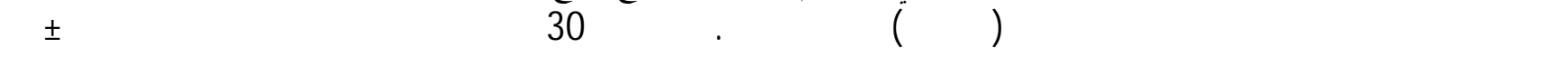

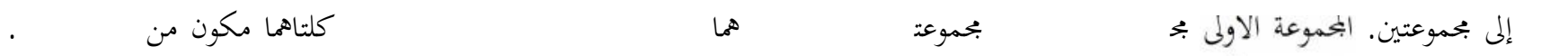

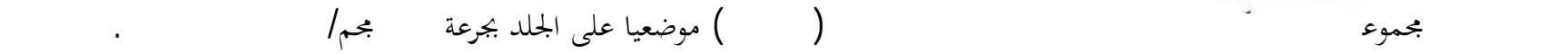

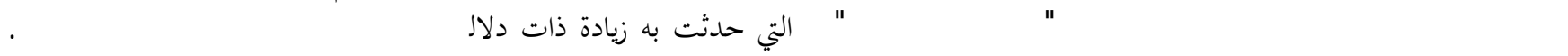

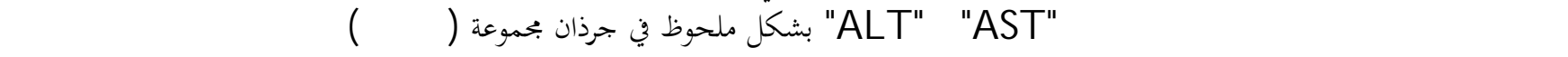

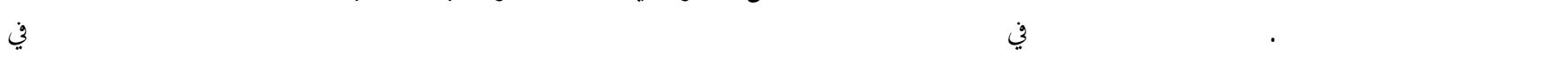

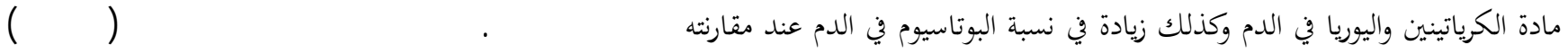

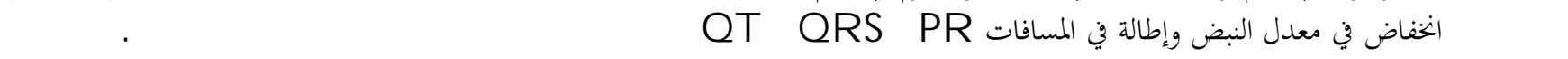

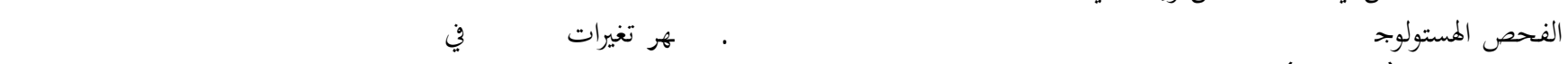

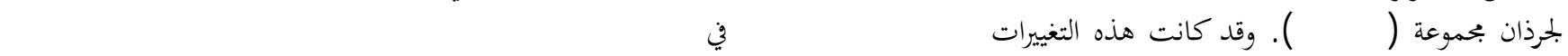

الضاطة.

$$
\begin{aligned}
& \text { ا قسم الطب الثرعي والسموم الإكلينيكية - كلية الطب - جامعة عين شمس }
\end{aligned}
$$

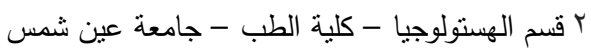

